\title{
Formulation of mucoadhesive microspheres of rosiglitazone maleate and its in vitro evaluation using ionotropic gelation technique
}

\section{Formulación de microesferas mucoadherentes de rosiglitazona maleato y su evalua- ción in vitro usando técnica de gelificación ionotrópica}

Akanksha Garud · Navneet Garud

School of Studies in Pharmaceutical Sciences, Jiwaji University, Gwalior, India

\author{
Artículo Original \\ Original Article \\ Correspondencia \\ Correspondence \\ Akanksha Garud \\ akanksha.garud@gmail.com \\ Financiación \\ Fundings \\ Trabajo realizado sin financiación. \\ Conflicto de interés \\ Competing interest \\ The authors declare that they have \\ no competing interests

\section{Agradecimientos} \\ Acknowledgements \\ Authors are thankful to Zydus Cadila, \\ Ahmedabad for providing gift sample \\ of the drug rosiglitazone.
}

Received: 17.10.2014 Accepted: 09.02.2015

\section{RESUMEN}

Objetivo. El objetivo del presente estudio es diseñar y evaluar las microesferas mucoadherentes de liberación controlada para uso oral.

Material y métodos. Las microesferas de rosiglitazona maleato con una capa de alginato y polímeros mucoadherentes de carboximetilcelulosa de sodio, carbopol 934P e hidroxipropilmetilcelulosa fueron elaboradas por un proceso de gelificación iónica de orificio. Las microesferas se evaluaron mediante rayos infrarrojos con transformado de Fourier, se estudio la morfología, el tamaño de partícula, las propiedades «micromeritics», el porcentaje de eficacia de entrapamiento, la prueba in vitro de «wash-off»y estudios in vitro de liberación.

Resultados. Las microesferas que resultaban eran esféricas y de flujo libre. La eficiencia de captura fue de 68,2 a $85,6 \%$. Las microesferas exhibieron buena propiedad mucoadherentes en el ensayo in vitro de lavado. La liberación lde las microesferas mucoadherentes de Rosiglitazona fue lento y se prolongado más de 12 h dependiendo de la composición de la capa.

Conclusiones. Las microesferas preparadas con mucoadherentes son convenientes para la liberación oral controlada de rosiglitazona maleato y así ayudar en el tratamiento de la diabetes mellitus tipo II.

Palabras clave: microesferas mucoadherentes, rosiglitazona maleato, liberación controlada.

\section{ABSTRACT}

Aim: The objective of the present study is to design and evaluate mucoadhesive microspheres for oral controlled release.

Materials and Method: Rosiglitazone maleate microspheres with a coat consisting of alginate and a mucoadhesive polymer sodium carboxymethylcellulose, carbopol 934P and hydroxypropylmethylcellulose were prepared by an orifice-ionic gelation process. The microspheres were evaluated for FTIR studies, morphology, particle size, micromeritic properties, percentage entrapment efficiency, in-vitro wash-off test and in-vitro release studies.

Results: The resulting microspheres were spherical and free flowing. The percent entrapment efficiency was 68.2 to $85.6 \%$. The microspheres exhibited good mucoadhesive property in the in vitro wash-off test. Rosiglitazone release from these mucoadhesive microspheres was slow and extended over $12 \mathrm{~h}$ duration of time depending on the composition of coat.

Conclusions: The prepared mucoadhesive microspheres are thus suitable for oral controlled release of Rosiglitazone maleate and thereby help in the management of type II diabetes mellitus.

Keywords: mucoadhesive microspheres, rosiglitazone maleate, sustained release. 


\section{INTRODUCTION}

Diabetes mellitus (DM) is a group of metabolic diseases characterized by hyperglycemia, hypertriglyceridaemia and hypercholesterolaemia, resulting from defects in insulin secretion or action or both ${ }^{1}$. Several attempts have been proposed to improve oral bioavailability, among them microencapsulation represents a promising concept ${ }^{2}$. Microencapsulation has been employed to sustain drug release, providing a long lasting and more reliable release with gastrointestinal (GI) irritation reduced or eliminated ${ }^{3}$.

Bioadhesive delivery of drugs has gained prominence in recent times as a means of drug administration. The intimate contact of the mucoadhesive polymer with the mucous surface can result in an increased drug retention time, increasing bioavailability and increasing contact time between drug and mucosa ${ }^{4,5,6}$. When the mucoadhesive dosage form is administered in either tablet or capsule form, they may or may not adhere to the mucous surface due to the weight of the dosage form and the vigorous movement of the GI tract, resulting in a large variation. However, mucoadhesive microspheres have some advantages. These include a light weight and a smaller dose variation due to the large number of microspheres administered ${ }^{7}$.

Rosiglitazone maleate (RSZ) is an antidiabetic drug for type II diabetes that improves insulin sensitivity in muscle and adipose tissues through activation of peroxidase proliferator-activated $\gamma$ receptor (PPAR $\gamma$ ) that are involved in the transcription of insulin responsive genes responsible for glucose production, transport, and utilization ${ }^{8}$. The aim of the present work is to characterize the rosiglitazone microspheres with biological half-life of 3-4 $\mathrm{h}$ and to evaluate the usefulness and feasibility of these microspheres for orally administered drug delivery system.

\section{MATERIALS AND METHODS}

\section{Materials}

Rosiglitazone (RSZ) was obtained from Zydus Cadila, Ahmedabad, India. Sodium alginate (CDH, New Delhi), Calcium chloride (Qualigens, Mumbai), Hydroxypropylmethylcellulose (HPMC), K4M, Sodium carboxymethylcellulose (SCMC) and carbopol-934P (CP) were procured from Central Drug House, Mumbai. All other reagents used were of analytical grade and purchased from their respective commercial sources.

\section{Methods}

\section{Preparation of Microspheres}

Rosiglitazone microspheres were prepared by ionotropic gelation method ${ }^{9}$ employing sodium alginate in combination with various polymers using sodium CMC, HPMC and carbopol 934P in different ratios (1:1, 1:9 and 9:1). Sodium alginate $(1.0 \mathrm{~g})$ was dissolved in purified water (50 $\mathrm{ml}$ ) to form a homogeneous polymer solution with $1.0 \mathrm{~g}$ of each polymer. The drug RSZ (2.0 g) was added to the polymer solution and the resulting dispersion was added manually drop wise into $10 \% \mathrm{w} / \mathrm{v}$ of calcium chloride solution (about $40 \mathrm{ml}$ ) through a syringe with a needle size no. 18. The added droplets were retained in the calcium chloride solution for $30 \mathrm{~min}$ to complete the curing reaction. The microspheres were collected by decantation, and the product thus separated was washed repeatedly with water and dried at $45^{\circ} \mathrm{C}$ for $12 \mathrm{hrs}$.

\section{FT-IR Study}

The Fourier transform infrared (FT-IR) spectra of pure drug (RSZ) and drug-polymer loaded microspheres were obtained using a Perkin-Elmer spectroscope. About 2-3 mg of samples were mixed with dried $\mathrm{KBr}$ of equal weight and compressed to form $\mathrm{KBr}$ disks. The samples were scanned from 400 to $4000 \mathrm{~cm}^{-1}$.

\section{Morphology and Particle size}

Shape and surface morphology of microspheres were studied using Scanning Electron Microscope (SEM LEO 430, Leo Electron Microscopy Ltd., England). For determination of surface characteristics all the microspheres were coated uniformly with gold palladium by using sputter coater for 5 to 7 minutes, after fixing the sample in individual steps. All samples of microspheres were then randomly examined for surface morphology at different magnification ranges.

Particle size of the microcapsules was evaluated using optical microscopy method ${ }^{10}$. Approximately 100 microspheres were counted for particle size determination using a calibrated optical microscope (Magnus MLX-DX). The experiments were done in triplicate $(n=3)^{11}$.

\section{Micromeritic Properties of Microspheres}

Accurately weighed microspheres were gently poured using a glass funnel into a graduated cylinder exactly to $10 \mathrm{ml}$ mark. Initial volume was noted. Bulk density and taapped 
density were noted using tapping method using measuring cylinder (of $10 \mathrm{ml}$ ).

Angle of repose of prepared microspheres $(n=3)$ was determined by fixed funnel standing method. The granules were allowed to flow through funnel orifice on a plane paper kept on the horizontal surface to form a pile of granules. Angle of repose $(\theta)$, Hausner's ratio $(\mathrm{H})$ and Carr's index (\% C) were calculated to study the flow properties of microspheres by using following formulas ${ }^{12}$.

$$
\theta=\tan ^{-1} \frac{\mathrm{h}}{\mathrm{r}}
$$

where, $\mathrm{h}$ is height and $\mathrm{r}$ is radius of the pile, respectively.

$$
\begin{gathered}
H=\frac{D t}{D b} \\
\% \mathrm{C}=\frac{D t-D b}{\mathrm{Dt}} \times 100
\end{gathered}
$$

where, $\mathrm{Dt}$ is tapped and $\mathrm{Db}$ is bulk density, respectively.

\section{Percentage Entrapment efficiency}

$50 \mathrm{mg}$ of microspheres were dispersed in $10 \mathrm{ml}$ of $0.1 \mathrm{~N}$ $\mathrm{HCl}$ for $30 \mathrm{~min}$ with occasional shaking. The suspension was then centrifuged at $2000 \mathrm{rpm}$ for $5 \mathrm{~min}$ and the supernatant was kept aside. The drug concentration was determined spectrophotometrically by UV at $228 \mathrm{~nm}$ (Shimadzu Pharmspec UV-1700, Japan). The entrapment efficiency $(n=3)$ was calculated by using following formula ${ }^{13}$.

$$
\% E E=\frac{D c a l}{D t h} \times 100
$$

where, Dcal is the calculated drug content and Dth is the theoretical drug content, respectively.

In-vitro wash-off test

Freshly excised pieces of intestinal mucosa $(5 \times 2 \mathrm{~cm})$ from sheep were mounted onto glass slides ( $3 \times 1$ inch) with adhesive material ${ }^{14}$. About 50 microspheres were spread onto each wet rinsed tissue specimen, and immediately thereafter the support was hung onto the arm of a U.S.P. tablet disintegrating test machine. By operating the disintegrating test machine the tissue specimen was given a slow, regular up and down movement in the test fluid at $37^{\circ} \mathrm{C}$ contained in a 11 vessel of the machine. At the end of one hr, and at hourly intervals up to $12 \mathrm{hrs}$, the machine was stopped and the number of microspheres still adhering to the tissue was counted. The test was performed at both simulated gastric fluid (0.1 N HCl, pH 1.2) and simulated intestinal fluid (phosphate buffer, $\mathrm{pH}$ 7.4). The mucoadhesiveness of the microspheres were compared with microspheres of a nonbioadhesive material, ethylene vinyl acetate (EVA).

In-vitro drug release of microspheres

A USP XXIII basket type dissolution apparatus was used to study in-vitro drug release from microspheres. A weighed amount of microspheres (50 mg) was used for the study. 900 $\mathrm{ml}$ of dissolution medium $(0.1 \mathrm{~N} \mathrm{HCl}, \mathrm{pH} 1.2)$ maintained at a temperature of $37 \pm 0.5^{\circ} \mathrm{C}$ and rotation speed of $100 \mathrm{rpm}$ was used for the study ${ }^{15}$. The in-vitro release studies were performed for $12 \mathrm{~h}$. At predetermined time intervals, $5 \mathrm{ml}$ sample was withdrawn, passed through a $0.45 \mu \mathrm{m}$ membrane filter (Millipore). After appropriate dilutions, the concentration of drug in samples were analysed spectrophotometrically at $228 \mathrm{~nm}$ using Shimadzu, Pharmspec UV-1700 series, Japan. The initial volume of dissolution medium was maintained by adding $5 \mathrm{ml}$ of fresh dissolution medium after each withdrawal. Perfect sink conditions prevailed during the in-vitro drug release studies.

\section{Statistical analysis}

Experimental results were performed in triplicate $(n=3)$ and expressed as mean \pm S.D. One-way analysis of variance (ANOVA) was applied to check significant difference in drug release from different formulations. Differences were considered to be significant at $\mathrm{P}<0.05$.

\section{RESULTS AND DISCUSSION}

\section{FTIR Study}

Potential chemical interaction between drug and polymer may change the therapeutic efficacy of the drug. To investigate the possibility of chemical interaction between drug and polymer, FTIR spectra of pure RGL and drug-loaded formulations containing different polymers were analyzed over the range $400-4000 \mathrm{~cm}^{-1}$. The IR spectra of pure RGL showed strong absorption bands attributable to carbonyl stretching at $1703 \mathrm{~cm}^{-1}$ and $\mathrm{C}=\mathrm{N}$ stretching of pyridine moiety at $1512 \mathrm{~cm}^{-1}$. FTIR spectra of the drug loaded formulations displayed all the characteristic bands of drug without any significant spectral shift. This suggested that there was no potential chemical interaction between the components of the microspheres (Spectras not shown).

\section{Physical characterization of microspheres}

The microspheres were found to be discrete, spherical and free-flowing. The effects of alginate concentrations and 
polymer ratios on the average particle size and \% drug entrapment of microspheres are shown in Table 1. The mean particle size increased with increase in polymer concentration which might be due to the fact that as polymer concentration increases it produces a significant increase in the viscosity, leading to an increase of the emulsion droplet size and finally a higher microsphere size.

The \% entrapment efficiency for the different formulations significantly increased with increasing polymer content $(p<0.05)$. The alginate-CP microspheres (9:1) produced the highest $\%$ entrapment efficiency of 85.6 \pm 3.2 . An increase in polymer concentration resulted in formation of larger microspheres entrapping greater amount of $\mathrm{drug}^{16}$.

The size of the microspheres increased with increase in the alginate concentration which may be due to the increase in viscosity, resulting in increase in droplet size during addition of the polymer dispersion to the harvesting medium. The SEM of prepared microspheres (F1) is shown in Figure 1. Formation of cracks on the surface of the microspheres were observed which may be due to the penetration of the dissolution medium into the microspheres and the subsequent dissolution of the drug and hence its diffusion through the polymer matrix.

Figure 1. SEM photograph of prepared microspheres (F1)

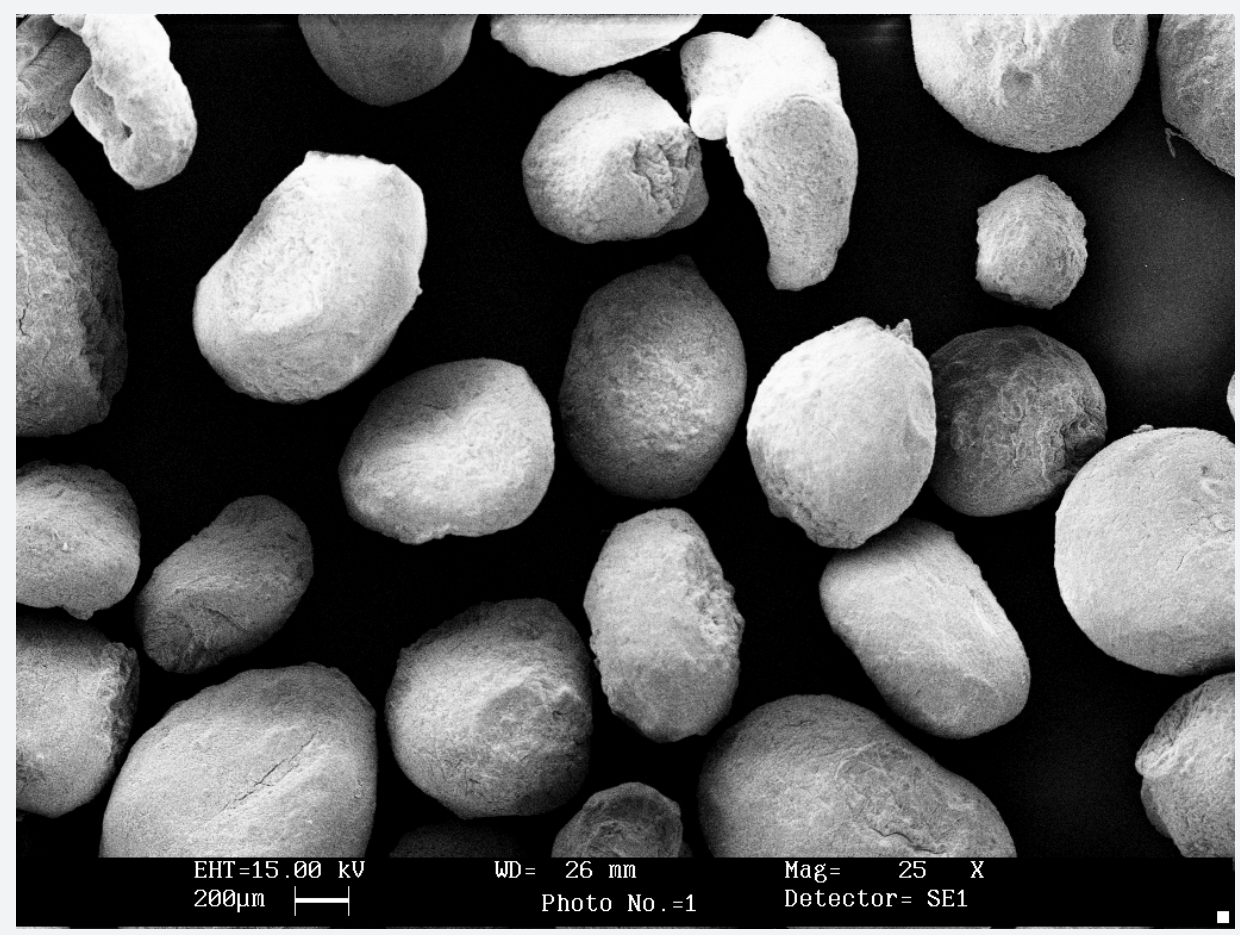

Table 1: Composition and evaluation of drug loaded microspheres

\begin{tabular}{|l|l|l|l|l|l|l|}
\hline Code & Coat composition & $\begin{array}{l}\text { \% entrapment } \\
\text { efficiency }\end{array}$ & Particle size & $\begin{array}{l}\text { Angle of } \\
\text { repose }\end{array}$ & $\begin{array}{l}\text { Carr's } \\
\text { index }\end{array}$ & Hausner's ratio \\
\hline F1 & Alg-SCMC (1:1) & $68.2 \pm 2.3$ & $404 \pm 3.5$ & $42^{\circ} 54^{\prime}$ & 9.8 & 1.04 \\
\hline F2 & Alg-SCMC (1:9) & $76.4 \pm 1.6$ & $412 \pm 5.5$ & $42^{\circ} 15^{\prime}$ & 10.2 & 1.08 \\
\hline F3 & Alg-SCMC (9:1) & $84.5 \pm 2.4$ & $438 \pm 2.8$ & $41^{\circ} 72^{\prime}$ & 11.2 & 1.12 \\
\hline F4 & Alg-HPMC (1:1) & $71.4 \pm 1.5$ & $426 \pm 5.2$ & $42^{\circ} 24^{\prime}$ & 10.7 & 1.06 \\
\hline F5 & Alg-HPMC (1:9) & $75.8 \pm 1.8$ & $435 \pm 4.5$ & $42^{\circ} 26^{\prime}$ & 10.8 & 1.11 \\
\hline F6 & Alg-HPMC (9:1) & $82.2 \pm 2.1$ & $459 \pm 3.8$ & $41^{\circ} 58^{\prime}$ & 11.5 & 1.14 \\
\hline F7 & Alg-CP (1:1) & $74.5 \pm 2.4$ & $488 \pm 4.2$ & $41^{\circ} 24^{\prime}$ & 11.7 & 1.09 \\
\hline F8 & Alg-CP(1:9) & $78.4 \pm 1.6$ & $500 \pm 2.8$ & $40^{\circ} 68^{\prime}$ & 12.2 & 1.12 \\
\hline F9 & Alg-CP (9:1) & $85.6 \pm 3.2$ & $510 \pm 3.4$ & $40^{\circ} 17^{\prime}$ & 12.8 & 1.16 \\
\hline
\end{tabular}




\section{Micromeritic properties of microspheres}

The rheological parameters like angle of repose, tapped density, bulk density and packing properties (Table 1) confirms better flow and packing properties of the prepared microspheres. All the formulation showed angle of repose value within the range of $30^{\circ}$ to $45^{\circ}(n=3)$, which is an appreciable limit for microspheres to show flow property while formulating in the dosage form.

\section{In-vitro wash-off studies}

The mucoadhesion test was performed on both simulated gastric $\mathrm{pH}(0.1 \mathrm{~N} \mathrm{HCl}, \mathrm{pH} 1.2)$ and simulated intestinal $\mathrm{pH}$ (phosphate buffer solution, PBS, $\mathrm{pH}$ 6.8) for $12 \mathrm{~h}$. The results are given in Table 2. Ch'ng et al. (1985) observed that the $\mathrm{pH}$ of the medium was critical for the degree of hydration, swelling and mucoadhesion of the polymers ${ }^{17}$. The wash-off was found to be faster at intestinal $\mathrm{pH}$ than at gastric $\mathrm{pH}$. The rapid wash-off observed at simulated intesti- nal pH 6.8 may be due to ionization of carboxyl acid group and other functional groups present in the polymers at this $\mathrm{pH}$, which increases their solubility and reduces adhesive strength.

The adhesion time of microspheres at $\mathrm{pH} 1.2$ was ranked, HPMC > carbopol 934P, whereas the adhesion time for the microspheres at $\mathrm{pH} 6.8$ was ranked, carbopol 934P > HPMC. Poor mucoadhesion of HPMC microspheres at alkaline $\mathrm{pH}$ may be due to its non-ionic nature possessing low hydrogen bonding capability with mucus glycoproteins ${ }^{18}$. Although carbopol 934P microspheres had negative charge repulsion with mucus, numerous hydrophilic functional groups such as carboxyl groups in carbopol molecules could form hydrogen bonds with mucus molecules, thus producing some adhesive force of this polymer. The microspheres produced using alginate: SCMC coat did not adhere to the mucosa for more than $6 \mathrm{~h}$ showing poor mucoadhesion in either of the $\mathrm{pH}$ mediums used for the study.

Table 2: Results of in-vitro wash-off test for the prepared microspheres

\begin{tabular}{|c|c|c|c|c|c|c|c|c|c|c|c|c|}
\hline \multirow{3}{*}{ Code } & \multicolumn{12}{|c|}{ Percent of microspheres adhering to tissue after $12 \mathrm{~h}$ duration } \\
\hline & \multicolumn{6}{|c|}{$0.1 \mathrm{~N} \mathrm{HCl}, \mathrm{pH} 1.2$} & \multicolumn{6}{|c|}{ Phosphate buffer, pH 6.8} \\
\hline & 1 & 2 & 4 & 6 & 8 & 12 & 1 & 2 & 4 & 6 & 8 & 12 \\
\hline F1 & $74 \pm 1.4$ & $70 \pm 0.5$ & $62 \pm 1.2$ & $56 \pm 0.8$ & $52 \pm 1.8$ & $18 \pm 1.2$ & $62 \pm 1.6$ & $20 \pm 1.1$ & $15 \pm 0.6$ & $10 \pm 0.4$ & - & - \\
\hline $\mathrm{F} 2$ & $78 \pm 2.5$ & $74 \pm 1.5$ & $70 \pm 1.8$ & $64 \pm 2.1$ & $58 \pm 1.5$ & $25 \pm 0.5$ & $68 \pm 2.2$ & $24 \pm 1.4$ & $18 \pm 0.5$ & $14 \pm 0.8$ & - & - \\
\hline F3 & $82 \pm 1.5$ & $74 \pm 1.6$ & $60 \pm 0.4$ & $38 \pm 1.2$ & $20 \pm 0.5$ & - & $70 \pm 1.5$ & $32 \pm 0.8$ & $18 \pm 1.2$ & $05 \pm 0.5$ & - & - \\
\hline $\mathrm{F} 4$ & $78 \pm 0.5$ & $75 \pm 0.6$ & $70 \pm 0.8$ & $66 \pm 1.2$ & $62 \pm 1.4$ & $52 \pm 1.8$ & $70 \pm 0.5$ & $48 \pm 2.2$ & $34 \pm 2.8$ & $21 \pm 0.5$ & $05 \pm 0.8$ & - \\
\hline F5 & $90 \pm 2.5$ & $84 \pm 2.4$ & $80 \pm 1.5$ & $76 \pm 1.2$ & $74 \pm 0.6$ & $72 \pm 1.8$ & $78 \pm 1.8$ & $60 \pm 2.1$ & $55 \pm 1.2$ & $42 \pm 1.7$ & $20 \pm 0.8$ & $04 \pm 0.2$ \\
\hline F6 & $82 \pm 1.2$ & $71 \pm 0.8$ & $66 \pm 0.4$ & $38 \pm 1.1$ & $28 \pm 0.4$ & $18 \pm 1.2$ & $70 \pm 1.2$ & $58 \pm 1.7$ & $32 \pm 1.1$ & $18 \pm 1.2$ & $08 \pm 0.2$ & - \\
\hline F7 & $80 \pm 2.2$ & $76 \pm 1.1$ & $70 \pm 1.4$ & $60 \pm 2.2$ & $55 \pm 1.1$ & $49 \pm 0.6$ & $72 \pm 1.4$ & $58 \pm 0.8$ & $62 \pm 1.1$ & $51 \pm 2.1$ & $32 \pm 2.1$ & $18 \pm 2.2$ \\
\hline F8 & $88 \pm 1.8$ & $85 \pm 1.2$ & $82 \pm 2.4$ & $78 \pm 1.5$ & $75 \pm 1.0$ & $68 \pm 1.2$ & $82 \pm 2.0$ & $76 \pm 0.8$ & $72 \pm 1.1$ & $64 \pm 0.8$ & $53 \pm 1.5$ & $28 \pm 2.2$ \\
\hline F9 & $75 \pm 2.1$ & $62 \pm 0.8$ & $56 \pm 0.5$ & $42 \pm 0.6$ & $35 \pm 1.4$ & $28 \pm 1.2$ & $72 \pm 1.2$ & $57 \pm 2.1$ & $48 \pm 1.4$ & $37 \pm 0.8$ & $22 \pm 1.7$ & $10 \pm 2.2$ \\
\hline EVA & $54 \pm 1.6$ & $40 \pm 1.8$ & $10 \pm 1.2$ & - & - & - & $52 \pm 1.0$ & $30 \pm 1.2$ & $06 \pm 2.2$ & - & - & - \\
\hline
\end{tabular}

EVA indicates ethylene vinyl acetate (non-mucoadhesive control). Values are given as mean \pm S.D.

\section{In-vitro drug release of microspheres}

Solubility of RSZ depends on $\mathrm{pH}$. Maximum absorption may be expected with increasing solubility in acid environment. It is known that microspheres constitute multipleunit dosage forms which have many advantages as compared to tablets. They spread more evenly in the stomach which leads to a decreased risk of high local concentration and of adverse effects. Moreover, these forms are characterized by a high reproducibility of release due to a relatively large surface and a short diffusion way of the drug ${ }^{19}$.

The in-vitro release studies were carried out in $0.1 \mathrm{~N} \mathrm{HCl}$ ( $\mathrm{pH}$ 1.2) which indicated that there was a slow and controlled release of drug for all the formulations. The drug release of the microspheres at 1:9 and 9:1 ratio of alginate: 
polymers are shown in Figure 2 and 3, respectively. Drug release from the RSZ microspheres was slow, extended and dependent on the type of polymer used. The increasing order of release rate observed with microspheres was Sodium alginate: Sodium CMC < Sodium alginate: Carbopol < Sodium alginate: HPMC. The differences in the drug release characteristics of various microspheres might be due to the differences in the porosity of the coat formed and its solubility in the dissolution fluid. Drug release from alginatesodium-CMC was slow and extended over a period of 12 $\mathrm{hr}$ and these microcapsules were found suitable for oral controlled release formulations.

Figure 2: Comparative in-vitro release study of formulations containing 1:9 ratio of alginate and mucoadhesive polymers

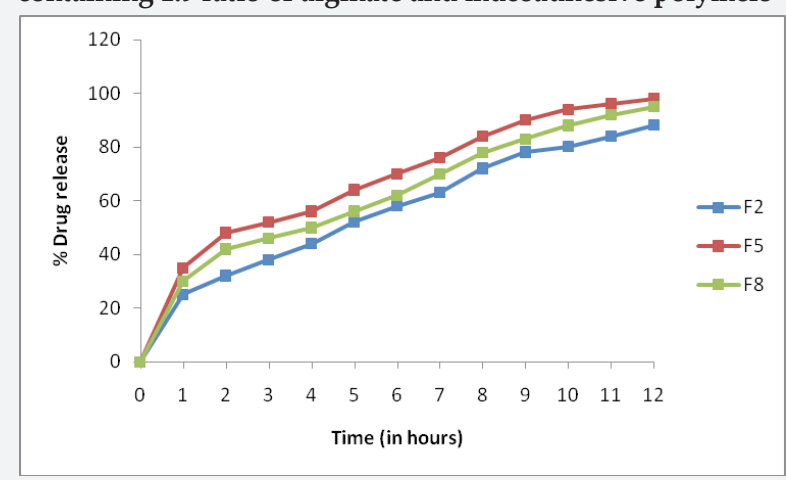

Figure 3: Comparative in-vitro release study of formulations containing 9:1 ratio of alginate and mucoadhesive polymers

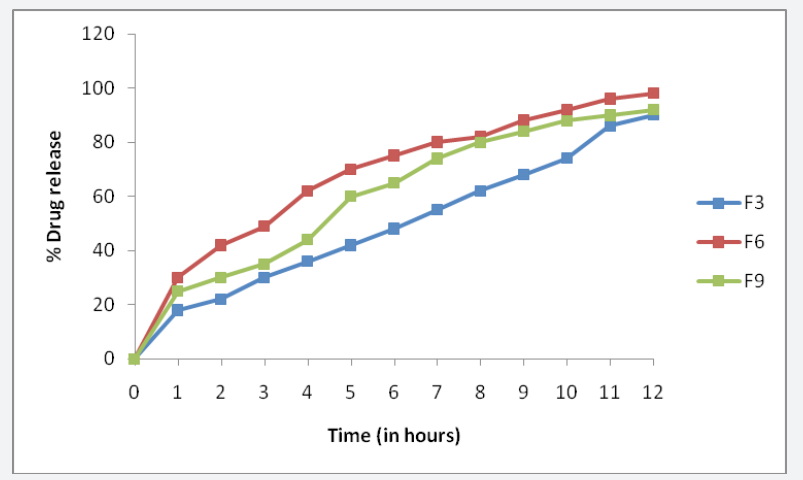

\section{CONCLUSIONS}

Mucoadhesive microspheres offer a unique carrier system owing to its capability to adhere to any mucosal tissue. This ionic orifice method produced spherical and free flowing microspheres. Rosiglitazone maleate release was found to be slow and extended period of time. The release depended on the type of polymer used. The release of drug was prolonged when incorporated within mucoadhesive polymers. The mucoadhesive microspheres prepared by ionotropic gelation technique gave sustained drug release up to $12 \mathrm{~h}$ duration. Microspheres containing alginate: sodium
CMC gave best reproducible results, would prove to be promising carrier for oral delivery of rosiglitazone maleate and thereby help in the management of type II diabetes mellitus.

\section{REFERENCES}

1. Tenpe CR, Yeole PG. Comparative evaluation of antidiabetic activity of some marketed polyherbal formulations in alloxan induced diabetic rats. Int J Pharm Tech Res. 2009; 1(1): 43-49

2. Silva CM, Ribeiro AJ, Ferreira D, Veiga F. Insulin encapsulation in reinforced alginate microspheres prepared by internal gelation. Eur J Pharm Sci. 2006; 29: 148-159

3. Lin WC, Yu DG, Yang MC. pH-sensitive polyelectrolyte complex gel microspheres composed of chitosan/sodium tripolyphosphate/dextran sulfate: swelling kinetics and drug delivery properties. Colloids and surfaces B: Biointerfaces. 2005; 44: 143-151

4. Adikwu MU, Yoshikawa Y, Takada K. Bioadhesive delivery of Metformin using prosopsis gum with antidiabetic potential. Bio Pharm Bull. 2003; 26(5): 662-666

5. Sachan NK and Bhattacharya A (2009) Modeling and characterization of drug release from glutinous rice starch based Hydrogel beads for controlled drug delivery. Int J Health Res. 2(1): 93-99

6. Bonacucina G, Martelli S, Palmieri GF. Rheological, mucoadhesive and release properties of carbopol gels in hydrophilic cosolvents. Int J Pharm. 2004; 282: 115-130

7. Chun MK, Cho CS, Choi HK. Mucoadhesive microspheres prepared by interpolymer complexation and solvent diffusion method. Int J Pharm. 2005; 288: 295-303

8. Kamila MM, Mondal N, Ghosh LK, Gupta BK. Multiunit floating drug delivery system of Rosiglitazone maleate: Development, characterization, statistical optimization of drug release and in vivo evaluation AAPS PharmSciTech. 2009; 10(3): 887-99.

9. Garud N, Garud A, Jain N. Formulation design and in-vitro evaluation of metformin microspheres using ionotropic gelation technique. Journal of Pharmacy Research. 2011; 4(7): 2103-2106

10. Lachman L, Lieberman HA, Kanig JL. The theory and practice of industrial pharmacy, $4^{\text {th }}$ Edition, Varghese Publishing House, Dadar, Bombay. 1991; 183-184

11. Badhana S, Garud N, Garud A. Colon Specific Drug Delivery of Mesalamine using Eudragit S100-coated chitosan microspheres for the treatment of ulcerative colitis. International Current Pharmaceutical Journal 2013; 2(3): 42-48

12. Chaudhary A, Garud N, Garud A. Formulation and in-vitro characterization of floating drug delivery system of Nateglinide. Am J PharmTech Res. 2013; 3(2): 477-486 
13. Garud N and Garud A. Preparation and In-vitro Evaluation of Metformin Microspheres using Non-aqueous Solvent Evaporation Technique, Trop J Pharm Res. 2012; 11(4): 577-583.

14. Chowdary KPR, Rao YS. Mucoadhesive microcapsules of glipizide: characterization, in vitro and in vivo evaluation. Indian J Pharm Sci, 2003; 65(3): 279-284

15. Nayak BS, Ghosh SK, Patro KTB. Preparation and characterization of famotidine microcapsule employing Mucoadhesive polymers in combination to enhance gastroretention for oral delivery. IJPPS. 2009; 1(2): 112-120

16. Swapna A, Mohd AB, Wamorkar V, Swathimutyam P. Formulation and Evaluation of Mesalamine Microspheres for Colon Targeted Drug Delivery System. Journal of Pharmacy Research. 2011; 4(6): 1670-1672.
17. Ch'ng HS, Park H, Kelly P, Robinson JR. For oral controlled delivery, II: synthesis and evaluation of some swelling, waterinsoluble bioadhesive polymers. J Pharm Sci. 1985; 74: 399405

18. El Hameed MDA, Kellaway IW. Preparation and in vitro characterization of mucoadhesive polymeric microspheres as intra-nasal delivery systems. Eur J Pharm Biopharm. 1977; 44: 53-60

19. Gangadharappa HV, Biswas S, Getyala A, Gupta VN, Pramod Kumar TM. Development, in vitro and in vivo evaluation of novel floating hollow microspheres of rosiglitazone maleate. Der Pharmacia Lettre. 2011; 3(4): 299-316 